\title{
Measurement of zinc stable isotope ratios in biogeochemical matrices by double-spike MC-ICPMS and determination of the isotope ratio pool available for plants from soil
}

\author{
Tim Arnold • Maria Schönbächler • Mark Rehkämper • \\ Schuofei Dong • Fang-Jie Zhao • Guy J. D. Kirk • \\ Barry J. Coles • Dominik J. Weiss
}

Received: 21 July 2010 /Revised: 14 September 2010 / Accepted: 14 September 2010 /Published online: 4 October 2010

(C) The Author(s) 2010. This article is published with open access at Springerlink.com

\begin{abstract}
Analysis of naturally occurring isotopic variations is a promising tool for investigating $\mathrm{Zn}$ transport and cycling in geological and biological settings. Here, we present the recently installed double-spike (DS) technique at the MAGIC laboratories at Imperial College London. The procedure improves on previous published DS methods in terms of ease of measurement and precisions obtained. The analytical method involves addition of a ${ }^{64} \mathrm{Zn}-{ }^{67} \mathrm{Zn}$ double-spike to the samples prior to digestion, separation of $\mathrm{Zn}$ from the sample matrix by ion exchange chromatogra-
\end{abstract}

T. Arnold · M. Schönbächler · M. Rehkämper · S. Dong •

B. J. Coles $\cdot$ D. J. Weiss

Imperial College London,

Department of Earth Science and Engineering,

London SW7 2AZ, UK

T. Arnold ( $\square)$

Scripps Institution of Oceanography, University of California,

San Diego, La Jolla, CA 92093, USA

e-mail: tarnold@ucsd.edu

M. Schönbächler

The University of Manchester, School of Earth, Atmospheric, and Environmental Science,

Manchester M13 9PL, UK

F.-J. Zhao

Rothamsted Research,

Harpenden, Herts AL5 2JQ, UK

G. J. D. Kirk

National Soil Resources Institute, Cranfield University,

Cranfield MK3 0AL, UK

D. J. Weiss

The Natural History Museum,

London SW7 5PD, UK phy, and isotopic analysis by multiple-collector inductively coupled plasma mass spectrometry. The accuracy and reproducibility of the method were validated by analyses of several in-house and international elemental reference materials. Multiple analyses of pure $\mathrm{Zn}$ standard solutions consistently yielded a reproducibility of about $\pm 0.05 \%$ o (2 SD) for $\delta^{66} \mathrm{Zn}$, and comparable precisions were obtained for analyses of geological and biological materials. Highly fractionated $\mathrm{Zn}$ standards analyzed by DS and standard sample bracketing yield slightly varying results, which probably originate from repetitive fractionation events during manufacture of the standards. However, the $\delta^{66} \mathrm{Zn}$ values (all reported relative to JMC Lyon $\mathrm{Zn}$ ) for two less fractionated in-house $\mathrm{Zn}$ standard solutions, Imperial $\mathrm{Zn}$ $(0.10 \pm 0.08 \%$ : 2 SD) and London $\mathrm{Zn}(0.08 \pm 0.04 \%)$, are within uncertainties to data reported with different mass spectrometric techniques and instruments. Two standard reference materials, blend ore BCR 027 and ryegrass BCR 281, were also measured, and the $\delta^{66} \mathrm{Zn}$ were found to be $0.25 \pm 0.06 \%$ ( $2 \mathrm{SD}$ ) and $0.40 \pm 0.09 \%$, respectively. Taken together, these standard measurements ascertain that the double-spike methodology is suitable for accurate and precise $\mathrm{Zn}$ isotope analyses of a wide range of natural samples. The newly installed technique was consequently applied to soil samples and soil leachates to investigate the isotopic signature of plant available $\mathrm{Zn}$. We find that the isotopic composition is heavier than the residual, indicating the presence of loosely bound $\mathrm{Zn}$ deposited by atmospheric pollution, which is readily available to plants.

Keywords Zinc isotopes - Stable isotope fractionation . Soil biogeochemistry · Double-spike - Mass bias correction . MC-ICPMS 


\section{Introduction}

Zinc isotopes can be fractionated by a number of chemical, biological, and physical processes. This characteristic provides the opportunity to investigate the bio-inorganic chemistry and cycling of this micronutrient element in the environment [1-3].

Over the past 10 years, efforts have been underway to use "non-traditional" naturally occurring isotopes in geochemical and cosmochemical studies whereby much information has been gained as to the magnitude of, and the processes that govern, $\mathrm{Zn}$ isotope fractionation $[1,2$, 4-20]. This research has initiated an interest in applying $\mathrm{Zn}$ naturally occurring isotope studies at a biological level to understand mechanisms of uptake [21-24] and to gain insights into how organisms are involved with nutrient cycling in the wider environment [10, 16, 25].

Essential for such studies are precise and accurate $\mathrm{Zn}$ isotope analyses applicable to a wide variety of samples. High-precision isotope measurements by MC-ICPMS are, however, easily affected by matrix problems, which can produce inaccuracies $[5,6,13,26]$. The adoption of a double-spike (DS) methodology for stable isotope analyses can overcome many of the most prevalent analytical problems. In particular, it enables a robust and precise correction for the instrumental mass bias and corrects for laboratory-induced isotope fractionations that may accompany incomplete element recovery during sample preparation. Despite these advantages, little attention has been given to the DS technique $[5,11]$.

The aim of this investigation was to develop a DS protocol for the accurate and precise determination of $\mathrm{Zn}$ isotope ratios and to provide confidence in the chosen spike combination. The performance of the DS technique was evaluated using a number of in-house and international standard reference materials. Following this, bulk soil from the Rothamsted farm (UK) and soil leachates were analyzed to characterize the $\mathrm{Zn}$ isotope pool available to plants in a natural setting. The results are discussed in relation to the soil's history. This work forms part of ongoing efforts to investigate the $\mathrm{Zn}$ isotope geochemistry in the soil-plant environment [16, 21, 22, 24].

\section{Experimental}

Analytical facilities and reagents

Sample preparation was carried out in Class 10 laminar flow benches within the class 1,000 clean room facility of the Imperial College MAGIC Laboratories. Mineral acids except for HF were purified from Analar grade by subboiling distillation in quartz stills. Distilled HF $(\sim 28 \mathrm{M}$
Ultrapure grade $)$ and $\mathrm{H}_{2} \mathrm{O}_{2}(\sim 30 \% v / v$ Aristar grade $)$ were purchased from VWR. For the anion exchange chromatography, $7 \mathrm{M} \mathrm{HCl}$ was made by mixing sub-boiled $(\sim 6 \mathrm{M})$ and Merck Suprapur ( $\sim 9 \mathrm{M}) \mathrm{HCl}$. All other acid dilutions used $>18.2 \mathrm{M} \Omega \mathrm{cm}^{-1}$ grade $\mathrm{H}_{2} \mathrm{O}$ from a Millipore purification system.

Sample digestion and $\mathrm{Zn}$ separation

Samples used in this study include two reference materials certified for elemental composition, blend ore BCR 027, previously analyzed by Chapman et al. [6], and the rye grass standard BCR 281. Also analyzed was a basalt from the East Pacific Rise (sample SO 40 31D from the Natural History Museum, London) and soil, obtained from the plow layer $(0-20 \mathrm{~cm})$ of an arable field on the Rothamsted farm, southeast England.

The rye grass standard BCR 281 digestion used a CEM Microwave Accelerated Reaction System MARS$\mathrm{X}$, with $100-\mathrm{ml}$ XP-1500 Teflon vessels. To approximately $0.35 \mathrm{~g}$ of plant material were added $5 \mathrm{ml} 9 \mathrm{M}$ $\mathrm{HNO}_{3}, 3 \mathrm{ml} 30 \% \mathrm{H}_{2} \mathrm{O}_{2}$, and $0.6 \mathrm{ml} 28 \mathrm{M} \mathrm{HF}$. The mixture was ramped to $210{ }^{\circ} \mathrm{C}$ and $250 \mathrm{psi}$ and held for $90 \mathrm{~min}$. Soil samples $(50 \mathrm{mg})$ were digested using the same protocol. Soil leaches were used as a technique to estimate the composition of the $\mathrm{Zn}$ pool available to the plants $[21,27]$. To this end, $30 \mathrm{ml} 0.1 \mathrm{M} \mathrm{HCl}$ was added to $0.3 \mathrm{~g}$ of air-dried soil, and the resulting suspension was stirred continuously for $48 \mathrm{~h}$ at $25^{\circ} \mathrm{C}$. The suspension was centrifuged, and the supernatant was collected. The basalt sample $(100 \mathrm{mg})$ was dissolved in $5 \mathrm{ml} 28 \mathrm{M} \mathrm{HF}$ and $2 \mathrm{ml} 15 \mathrm{M} \mathrm{HNO}_{3}$ at $120{ }^{\circ} \mathrm{C}$ on a hotplate for $48 \mathrm{~h}$. The $\mathrm{Zn}$ blend ore BCR-027 (100 mg) was dissolved in $4 \mathrm{ml} 15 \mathrm{M} \mathrm{HNO}_{3}$ and $1 \mathrm{ml} 6 \mathrm{M} \mathrm{HCl}$ at $120{ }^{\circ} \mathrm{C}$ on a hotplate for $48 \mathrm{~h}$.

After digestion, samples were evaporated to dryness, and the residue was dissolved in $\sim 1 \mathrm{ml} 7 \mathrm{M} \mathrm{HCl}$ with $0.05 \mathrm{ml} 30 \% \mathrm{H}_{2} \mathrm{O}_{2}$ added to prevent reduction of ferric Fe. The solutions were dried again and redissolved in $2.5 \mathrm{ml} 7 \mathrm{M} \mathrm{HCl}$ containing $0.001 \% \mathrm{H}_{2} \mathrm{O}_{2}$ by volume. These solutions were split into three aliquots: (1) $0.5 \mathrm{ml}$ for preliminary $\mathrm{Zn}$ concentration measurements, (2) $1 \mathrm{ml}$ for anion exchange chromatography to purify $\mathrm{Zn}$ for isotopic analysis, and (3) $1 \mathrm{ml}$ for archive. The $0.5-\mathrm{ml}$ aliquots for concentration measurement were first diluted to $3.5 \mathrm{ml}$ and made up to $1 \mathrm{M} \mathrm{HCl}$. These solutions were analyzed for $\mathrm{Zn}$ concentrations by inductively coupled plasma atomic emission spectroscopy (ICP-AES on a Vista PRO (Varian, Inc.) at the EMMA Laboratories of the Natural History Museum, London. The concentration data were used to ensure that an optimal amount of Zn DS was added to the sample solution prior to anion exchange chromatography. 
The separation of Zn from matrix utilized Bio-Rad PolyPrep columns that were filled with $2 \mathrm{ml}$ of AG MP-1 100200 mesh anion exchange resin. The resin was conditioned with $7 \mathrm{M} \mathrm{HCl}(10 \mathrm{ml})$ and successively washed with $0.08 \mathrm{M} \mathrm{HNO}_{3}(10 \mathrm{ml}), \mathrm{H}_{2} \mathrm{O}(10 \mathrm{ml}), 0.08 \mathrm{M} \mathrm{HNO}_{3}(10 \mathrm{ml})$ and $\mathrm{H}_{2} \mathrm{O}(10 \mathrm{ml})$. This was followed by re-conditioning with $7 \mathrm{M} \mathrm{HCl}-0.001 \% \mathrm{H}_{2} \mathrm{O}_{2}(7 \mathrm{ml})$ and loading of the samples $\left(1 \mathrm{ml}\right.$ solution in $\left.7 \mathrm{M} \mathrm{HCl}-0.001 \% \mathrm{H}_{2} \mathrm{O}_{2}\right)$. The majority of matrix elements were first eluted using $30 \mathrm{ml}$ $7 \mathrm{M} \mathrm{HCl}-0.001 \% \mathrm{H}_{2} \mathrm{O}_{2}$, followed by elution of $\mathrm{Fe}$ in $17 \mathrm{ml}$ $2 \mathrm{M} \mathrm{HCl}$ (for separate isotope analysis). If $\mathrm{Fe}$ was not collected then all matrix elements were removed with $17 \mathrm{ml}$ $2 \mathrm{M} \mathrm{HCl}$. Finally, $\mathrm{Zn}$ was eluted from the columns with $12 \mathrm{ml} 0.1 \mathrm{M} \mathrm{HCl}$. The resin was then washed with $10 \mathrm{ml}$ $0.5 \mathrm{M} \mathrm{HNO}_{3}$, after which it could be used again for further separations.

The $\mathrm{Zn}$ fraction was dried down, dissolved in $0.2 \mathrm{ml}$ $15 \mathrm{M} \mathrm{HNO}_{3}$, and dried again to drive off residual $\mathrm{HCl}$. Finally, $1 \mathrm{ml} 0.1 \mathrm{M} \mathrm{HNO}_{3}$ was added and the samples refluxed for $>2 \mathrm{~h}$ to ensure complete dissolution. The solutions were then ready to be analyzed with the $N u$ Plasma MC-ICPMS.

For the plant samples that were digested using a microwave oven, the total procedural $\mathrm{Zn}$ blank from dissolution and the ion exchange separation was $60 \pm$ $15 \mathrm{ng}$, which represents $\sim 1 \%$ of the total $\mathrm{Zn}$ for the samples with the lowest concentrations. For the rock samples that were dissolved in the clean room on a hotplate, the procedural $\mathrm{Zn}$ blank was lower than $20 \mathrm{ng}$, which is small considering that these samples contained at least $5 \mu \mathrm{g} \mathrm{Zn}$. The effect of these blank contributions on the final isotopic results was essentially negligible when compared to the measurement uncertainty, and no correction was therefore applied.

Mass spectrometry and double spike

\section{Double-spike design}

Zinc has five stable isotopes, ${ }^{64} \mathrm{Zn}(48.63 \%),{ }^{66} \mathrm{Zn}$ (27.90\%), ${ }^{67} \mathrm{Zn}(4.10 \%),{ }^{68} \mathrm{Zn}(18.75 \%)$, and ${ }^{70} \mathrm{Zn}$ $(0.62 \%)$, four of which are needed to implement a DS approach for stable isotope analysis. Numerical methods, adapted from Galer [28], were used to identify spike compositions that provide near-optimal $\left(\sim 90^{\circ}\right)$ intersection angles between the mass fractionation vectors of spiked and unspiked samples, as well as minimal error magnification factors over a wide range of spike-sample ratios. These calculations demonstrate that a Zn DS enriched in ${ }^{64} \mathrm{Zn}$ and ${ }^{67} \mathrm{Zn}$ with a molar ratio of ${ }^{64} \mathrm{Zn} /{ }^{67} \mathrm{Zn} \approx 2.5$ provides the most favorable results if the equations are solved in ${ }^{64} \mathrm{Zn} /{ }^{67} \mathrm{Zn}-{ }^{66} \mathrm{Zn} /{ }^{67} \mathrm{Zn}-{ }^{68} \mathrm{Zn} /{ }^{67} \mathrm{Zn}$ isotope space. The calculations also indicate that this DS is ideally used with a molar fraction of spike derived to total $\mathrm{Zn}$ of between 0.5 and 0.6 . This yields molar ratios ${ }^{64} \mathrm{Zn} /{ }^{66} \mathrm{Zn} /{ }^{67} \mathrm{Zn} /{ }^{68} \mathrm{Zn}$ for the sample spike mixture of about 5.2:1.4:1.5:1. These differ from those of the ${ }^{64} \mathrm{Zn}-{ }^{67} \mathrm{Zn}$ DS techniques of Bermin et al. [5] and John et al. [11] that are best used at molar ratios of 4.5:1.4:1.8:1 and 4.2:1.3:1.6:1, respectively.

Recently, Rudge et al. [29] published a thorough evaluation of possible double spikes for all elements with at least four naturally occurring isotopes. They identified the most suitable compositions using error propagation techniques on all possible spike combinations. We used the MATLAB codes made available by Rudge et al. [29] to compare the characteristics of our Zn DS with other favorable compositions. A number of factors made the inclusion of ${ }^{70} \mathrm{Zn}$ difficult. These were (1) difficulties in expanding the measurable mass range in terms of instrumental mass dispersion, (2) the high cost of purified ${ }^{70} \mathrm{Zn}$, and (3) the spectral interference ${ }^{54} \mathrm{Fe}^{16} \mathrm{O}^{+}$and ${ }^{70} \mathrm{Ge}^{+}$. With all other parameters remaining at default values, the methods of Rudge et al. [29] indicate that the optimal composition of a ${ }^{64} \mathrm{Zn}-{ }^{67} \mathrm{Zn}$ DS is ${ }^{64} \mathrm{Zn} /{ }^{67} \mathrm{Zn}=4.88$, which differs from the composition chosen for this study $\left({ }^{64} \mathrm{Zn} /{ }^{67} \mathrm{Zn} \approx 2.51\right)$; however, the effect on error propagation and the range of optimal spike sample ratios is small (Fig. 1). Further calculations indicate that two other spike combinations $\left({ }^{6}{ }^{66} \mathrm{Zn}-{ }^{67} \mathrm{Zn}\right.$ and a ${ }^{66} \mathrm{Zn}-{ }^{68} \mathrm{Zn}$ DS) may be superior to a ${ }^{64} \mathrm{Zn}-{ }^{67} \mathrm{Zn}$ DS considering the error propagated on the natural fractionation factor $(\alpha)$. However, the maximum possible error reduction is only about $25 \%$ (Fig. 1). This and the results obtained in this study thus suggest that a suitable and robust DS composition was chosen for the $\mathrm{Zn}$ isotope measurements.

The $\mathrm{Zn}$ DS was prepared as a mixture of two concentrated spike solutions that are enriched in ${ }^{64} \mathrm{Zn}$ and ${ }^{67} \mathrm{Zn}$, respectively. $21.3 \mathrm{mg}$ of ${ }^{64} \mathrm{Zn}$ metal $(99.30 \%$ purity; Isoflex Corp., USA) and $10.9 \mathrm{mg}{ }^{67} \mathrm{Zn}(89.60 \%$ purity; Oak Ridge National Laboratory, USA) were each separately dissolved in $2 \mathrm{M} \mathrm{HNO}_{3}$. The $\mathrm{Zn}$ concentrations of the solutions were determined by reverse isotope dilution mass spectrometry to plan the preparation of the final DS solution. Suitable volumes of the individual spikes were then mixed to obtain a DS solution, which was characterized by ${ }^{64} \mathrm{Zn} /{ }^{67} \mathrm{Zn} \approx 2.5$ (Table 1 ) and a total $\mathrm{Zn}$ concentration of $5.1 \mu \mathrm{g} \mathrm{g}^{-1}$.

The isotopic composition of the DS was determined by repeated MC-ICPMS analyses conducted during three separate analytical sessions over a period of six months. These measurements were carried out relative to a standard solution of natural $\mathrm{Zn}$, hereafter named "London $\mathrm{Zn}$," which was prepared in our laboratory from a $\mathrm{Zn}$ wire of 99.9985\% purity (Alfa Aesar, Puratronic grade). The Zn wire was first leached with $0.1 \mathrm{M} \mathrm{HNO}_{3}$, washed with water and ethanol, and then dissolved in $2 \mathrm{M} \mathrm{HNO}_{3}$. 


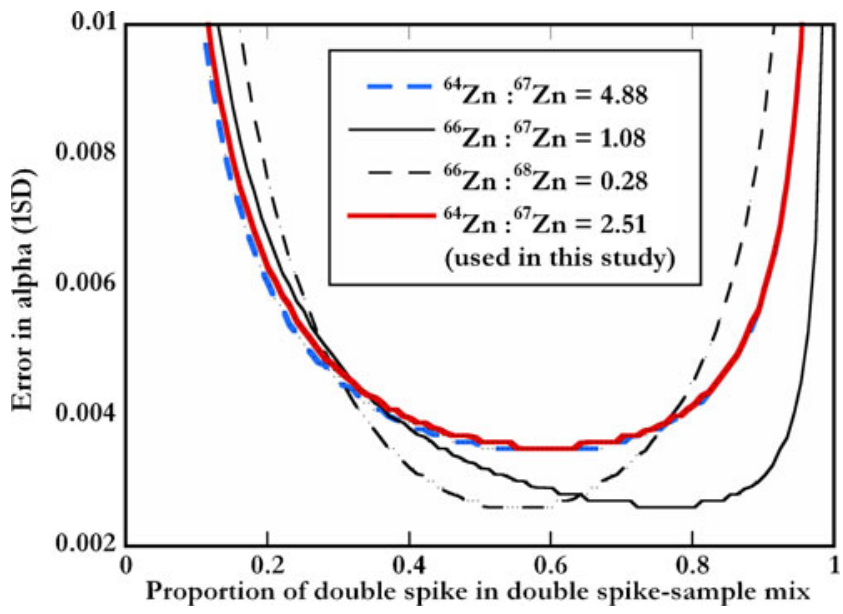

Fig. 1 Results obtained from the evaluation of four favorable $\mathrm{Zn}$ double-spike compositions with the MATLAB error minimization code of Rudge et al. [29]. The curves denote the uncertainty in the natural fractionation factor $\alpha$ as a function of the proportion of double spike in the spike sample mixture. The results indicate that the double spike used in the present study (with ${ }^{64} \mathrm{Zn} /{ }^{67} \mathrm{Zn}=2.51$ ) can be used over a wide range of spike sample ratios and yields only marginally less precise results than alternative compositions

The isotopic analyses of the spike used external normalization to $\mathrm{Cu}$ and the exponential law for mass bias correction:

$R_{\mathrm{Zn}}=r_{\mathrm{Zn}}\left(\frac{66}{64}\right)^{f}$

where $R_{Z n}$ and $r_{Z n}$ denote the "true" and measured ${ }^{66} \mathrm{Zn} /{ }^{64} \mathrm{Zn}$ ratios, respectively, and the number is the atomic mass of the relevant isotope (integer values shown for simplicity). The fractionation factor $f$ is given by:

$f=\frac{\ln \left(\frac{R_{\mathrm{Cu}}}{r_{\mathrm{Cu}}}\right)}{\ln \left(\frac{65}{63}\right)}$

where $R_{\mathrm{Cu}}$ is a presumed ${ }^{65} \mathrm{Cu} /{ }^{63} \mathrm{Cu}$ ratio for the copper dopant and $r_{\mathrm{Cu}}$ is the measured ratio.

The ${ }^{65} \mathrm{Cu} /{ }^{63} \mathrm{Cu}$ ratio applied as $R_{\mathrm{Cu}}$ in Eq. 2 was optimized for each measurement session from interspersed analyses of the London $\mathrm{Zn}$ solution doped with $\mathrm{Cu}$. Recalculation of the ${ }^{65} \mathrm{Cu} /{ }^{63} \mathrm{Cu}$ ratio was necessary in order to account for changes in the mass bias behavior between $\mathrm{Zn}$ and $\mathrm{Cu}$ on the day (this effect is further discussed in section Double-spike sample analysis protocol). A ${ }^{65} \mathrm{Cu} /{ }^{63} \mathrm{Cu}$ ratio was chosen, such that mass bias correction relative to ${ }^{65} \mathrm{Cu} /{ }^{63} \mathrm{Cu}$ and internal normalization relative to the reference ratio of ${ }^{66} \mathrm{Zn} /{ }^{64} \mathrm{Zn}=0.565023$ (from Rosman [30]) produced identical results for ${ }^{64} \mathrm{Zn} /{ }^{67} \mathrm{Zn},{ }^{66} \mathrm{Zn} /{ }^{67} \mathrm{Zn}$, and ${ }^{68} \mathrm{Zn} /{ }^{67} \mathrm{Zn}$. The optimized ${ }^{65} \mathrm{Cu} /{ }^{63} \mathrm{Cu}$ ratio was then used for the mass bias correction of the pure $\mathrm{Zn}$ DS solution (Table 1). This procedure implies that the isotope ratios of the DS were determined relative to the "normal" $\mathrm{Zn}$ isotope composition and relative to the reference ratio of ${ }^{66} \mathrm{Zn} /{ }^{64} \mathrm{Zn}$ of 0.565023 . The $\mathrm{Zn}$ concentrations of the standard and spike solutions were accurately matched for these measurements and potential matrix effects due to different acid concentrations were avoided by drying down and re-dissolving suitable aliquots of the concentrated Zn DS and London Zn stock solutions in $0.1 \mathrm{M} \mathrm{HNO}_{3}$ prior to analysis. Thus, the mass bias behavior of $\mathrm{Cu}$ isotopes between standard and spike analyses remained identical, and a correction on the $\mathrm{Zn}$ isotope ratios could be made. This technique is analogous to that used by Siebert et al. [31] in calculating the Mo spike isotope composition by doping with $\mathrm{Pd}$ and by Weiss et al. [32] in calculating the $\mathrm{Tl}$ spike isotope composition during $\mathrm{Pb}$ isotope measurements using $\mathrm{MC}$ ICPMS.

\section{Double-spike measurement protocol}

All isotopic measurements were performed with a $\mathrm{Nu}$ Plasma MC-ICPMS instrument, connected to a DSN-100 (Nu Instruments) desolvating sample introduction system that was operated with a CETAC Aspire nebulizer. The collector configuration is given in Table 2. Four $\mathrm{Zn}$ isotopes and ${ }^{62} \mathrm{Ni}$ were measured simultaneously with the Faraday cups, all equipped with $10^{11} \Omega$ resistors. The ion beam of ${ }^{62} \mathrm{Ni}$ was monitored to correct for the isobaric interference on ${ }^{64} \mathrm{Zn}$ from ${ }^{64} \mathrm{Ni}$.

Table 1 Average $\mathrm{Zn}$ isotope compositions determined for London $\mathrm{Zn}$ and the $\mathrm{Zn}$ double spike

\begin{tabular}{lcrrr}
\hline Solution & Number & \multicolumn{1}{c}{${ }^{64} \mathrm{Zn} /{ }^{67} \mathrm{Zn}$} & ${ }^{66} \mathrm{Zn} /{ }^{67} \mathrm{Zn}$ & ${ }^{68} \mathrm{Zn} /{ }^{67} \mathrm{Zn}$ \\
\hline $\mathrm{JMC}$ London $\mathrm{Zn}{ }^{\mathrm{a}}$ & 175 & $12.161276(1400)$ & $6.871420(750)$ & $4.554100(490)$ \\
${ }^{64} \mathrm{Zn}-{ }^{67} \mathrm{Zn} \mathrm{DS}^{\mathrm{b}}$ & 31 & $2.505641(7200)$ & $0.056089(5300)$ & $0.060645(3500)$ \\
\hline
\end{tabular}

The uncertainties given in parentheses denote two standard deviations and they apply to the least significant digits. $n=$ number of measurements

${ }^{\mathrm{a}}$ The isotopic data for the London $\mathrm{Zn}$ solution were obtained over a period of 6 months by internal normalization relative to ${ }^{66} \mathrm{Zn} /{ }^{64} \mathrm{Zn}=0.565023$ with the exponential law

${ }^{\mathrm{b}}$ The isotope data for the Zn DS were acquired during four measurement sessions over a period of 6 months by empirically optimized external normalizations relative to admixed $\mathrm{Cu}$ (see text for details) 
Table $2 \mathrm{Nu}$ Plasma collector configuration, natural isotope abundances for relevant elements, and typical ion beam intensities encountered in measurements conducted with optimal spike sample ratios

\begin{tabular}{|c|c|c|c|c|c|c|c|}
\hline Mass & 68 & 67 & 66 & 65 & 64 & 63 & 62 \\
\hline Collector & $\mathrm{H} 4$ & $\mathrm{H} 2$ & $\mathrm{Ax}$ & L2 & L3 & L4 & L5 \\
\hline Isotopes & ${ }^{68} \mathrm{Zn}$ & ${ }^{67} \mathrm{Zn}$ & ${ }^{66} \mathrm{Zn}$ & & ${ }^{64} \mathrm{Zn}$ & & ${ }^{62} \mathrm{Ni}$ \\
\hline \multirow[t]{3}{*}{ Abundances (\%) } & (18.8) & $(4.1)$ & (27.9) & & $(48.6)$ & & (3.6) \\
\hline & & & & ${ }^{65} \mathrm{Cu}$ & & ${ }^{63} \mathrm{Cu}$ & \\
\hline & & & & $(30.8)$ & & $(69.2)$ & \\
\hline
\end{tabular}

(0.9)

Typical ion beam intensities $\left(\begin{array}{llllll}\left(10^{-11} \mathrm{~A}\right)^{\mathrm{a}} & 1.6 & 2.4 & 2.2 & \mathrm{n} / \mathrm{a} & 8.5\end{array}\right.$
${ }^{\text {a }}$ For a spiked sample solution with $200 \mathrm{ng} \mathrm{ml}^{-1} \mathrm{Zn}$ dissolved in $0.1 \mathrm{M} \mathrm{HNO}_{3}$

\section{Zn isotope notation}

f $5 \mathrm{~s}$, in blocks of 20 . Prior to each block, the baseline signals were monitored for $15 \mathrm{~s}$, while the ion beam was deflected by the electrostatic analyzer; these data were subsequently subtracted from the measured ion beam intensities. This approach ignores any residual (memory) signals from previously analyzed sample or standard solutions. Tests showed that a further correction was not necessary because the memory signals contributed less than $0.4 \%$ to the ion beam intensities that were employed for isotopic measurements in this study. Each analysis was followed by a washout, whereby the sample introduction system was flushed with $0.1 \mathrm{M} \mathrm{HNO}_{3}$ for $100 \mathrm{~s}$.

A complete sample analysis, excluding washout, required about 6 min and consumed $\sim 500 \mu \mathrm{l}$ sample solution. The instrumental sensitivity for $\mathrm{Zn}$ was usually 70 to 80 $\mathrm{V} / \mathrm{ppm}$. Analyses using an $8 \mathrm{~V}$ ion beam for ${ }^{64} \mathrm{Zn}$ (Table 2) therefore required $\sim 50 \mathrm{ng}$ of natural $\mathrm{Zn}$.

\section{Double-spike data reduction}

The $\mathrm{Zn}$ isotope data collected during the mass spectrometric analyses represent the "raw" $\mathrm{Zn}$ isotope compositions of the spike-sample mixtures. These data were processed to calculate the "true" mass-bias-corrected isotope compositions of the unspiked-samples. The DS data reduction was performed off-line, using a previously described iterative method [31]. The procedure applies a geometric approach to solve the DS equations in threedimensional isotope space defined by isotope ratios with a common denominator [33]. It is particularly suitable for the accurate reduction of data collected by MC-ICPMS because it does not make the simplifying assumption that the instrumental mass bias can be described by a linear law. This assumption has been used for some measurements by thermal ionization mass spectrometry [28]; however, the mass bias of MC-ICPMS is at least an order of magnitude larger. Therefore, an iterative procedure is used, which accounts for the curved trajectories that are obtained, when mass discrimination is described using the exponential law [31].
The $\mathrm{Zn}$ isotope data are reported relative to an isotope standard using the $\delta$ notation:

$\delta^{\mathrm{x} / \mathrm{y}} \mathrm{Zn}=\left(\frac{R_{\text {sample }}}{R_{\text {standard }}}-1\right) \times 10^{3}$

where $R_{\text {sample }}$ and $R_{\text {standard }}$ denote the ${ }^{\mathrm{x}} \mathrm{Zn} /{ }^{\mathrm{y}} \mathrm{Zn}$ isotope ratio of the sample and standard, respectively, and where $x$ and $y$ denote the isotope masses. In this study, $\mathrm{Zn}$ isotope ratios are generally quoted as $\delta^{66 / 64} \mathrm{Zn}$ values, which are abbreviated as $\delta^{66} \mathrm{Zn}$.

\section{Standard sample bracketing protocol}

A standard sample bracketing (SSB) method was used for analyses of matrix-free $\mathrm{Zn}$ standard solutions to obtain additional and precise isotope data that were used to evaluate the DS technique. The SSB approach assumes that any temporal drift in mass bias between bracketing standards is predictable and approximates to a linear interpolation. This requires the mass bias to change smoothly during the course of a measurement session, without significant jumps between adjacent analyses. The sample and standard measurements by SSB comprised 20 integrations of $5 \mathrm{~s}$ each, in one block. The procedures employed for baseline and interference corrections remained identical to the DS protocol, as did the collector setup (Table 2). Results were obtained by inserting the "raw" average ${ }^{66} \mathrm{Zn} /{ }^{64} \mathrm{Zn}$ (or ${ }^{67} \mathrm{Zn} /{ }^{64} \mathrm{Zn},{ }^{68} \mathrm{Zn} /{ }^{64} \mathrm{Zn}$ ) ratios for each sample into Equation 3, along with the mean result determined for the two bracketing standards.

\section{Results and discussion}

Double-spike sample analysis protocol

The London $\mathrm{Zn}$ standard was used as the in-house "zerodelta" reference material during this study. Repeated 
measurements of solution mixtures, prepared from $\mathrm{Zn}$ DS and London $\mathrm{Zn}$ with a near-optimal molar proportion of spike-derived relative to total $\mathrm{Zn}$ (approximately 0.55), were carried out during each analytical session. These mixtures commonly exhibited small deviations from $\delta^{66} \mathrm{Zn}=0$, in line with observations of previous studies using double spikes in conjunction with MC-ICPMS [5, 34, $35]$. These small but significant variations $(<1 \%)$ appear to reflect changes in the instrumental mass bias, which produce fractionation patterns that deviate from exponential law behavior [36]. The generalized power law can be employed to accurately describe complex mass bias characteristics, but the exponential law was nonetheless implemented in this study because this approach is (1) more straightforward and (2) has been shown to provide accurate and precise stable isotope data if a simple empirical correction is employed to correct for this offset [34].

The offset corrections were performed by referencing the sample data of a measurement session to the mean isotopic composition determined from repeated analyses of a $\mathrm{Zn}$ DS-London Zn mixture:

$$
\begin{aligned}
& \delta^{66} \mathrm{Zn}_{\text {sample(true) }}{ }^{=} \delta^{66} \mathrm{Zn}_{\text {sample(measured) }} \\
& -\mathrm{Zn}_{\text {London(measured) }}
\end{aligned}
$$

Over time periods of minutes to several (2-5) hours, the $\mathrm{Zn}$ DS-London $\mathrm{Zn}$ mixtures displayed isotope compositions that were essentially constant within the measurement precision (Fig. 2a). Small isotopic variations were seen on some days over periods of about 10-20 h (Fig. 2b). Contamination of the system was carefully monitored and could not account for the variation. When present, such trends were usually gradual and could be approximated by a linear interpolation for the correction of the data. For the results shown in Fig. $2 b$, the application of such a correction improved the precision of the repeated London $\mathrm{Zn}$ analyses from \pm 0.08 to $\pm 0.04 \%$ (2SD) for $\delta^{66} \mathrm{Zn}$.

Bermin et al. [5] accounted for the small day-to-day deviations of the "zero-delta" standard using daily measurements of the natural $\mathrm{Zn}$ isotope composition for a natural standard, and applying this composition in the DS data reduction routine for samples analyzed on the same day. This approach, however, suffers from the drawback that the natural $\mathrm{Zn}$ isotope composition must be re-determined if there are larger drifts in mass bias behavior during the course of longer measurement sessions (e.g., Fig. 2b).

Each sample was measured four times during an analytical session, and these analyses yielded precisions (2SD) for $\delta^{66} \mathrm{Zn}$ of between $\pm 0.06 \%$ and $\pm 0.15 \%$, depending on instrument stability (Table 3 ). The average uncertainty of sample measurements was similar to the external precision (2SD) obtained for multiple analyses of a London $\mathrm{Zn}$ solution conducted during the same time interval. (NB: Uncertainties given in the text are always specific to the measurement made; average uncertainties are not used.)

A number of analyses were performed to ascertain that the DS technique could be used for accurate determination of $\mathrm{Zn}$ isotope compositions over a sensibly large range of spike sample ratios (Fig. 3). The $\mathrm{Zn}$ isotope compositions of $\mathrm{Zn}$ DS-London $\mathrm{Zn}$ mixtures with variable proportions of Zn DS were analyzed relative to a mixture with a DSderived $\mathrm{Zn}$ proportion of $P \approx 0.55$ (Fig. 3). The results demonstrate that the DS methodology yields accurate results when the DS contributes about $40 \%$ to $70 \%$ of the total $\mathrm{Zn}$ present in DS sample mixtures. At higher and lower proportions, the precision and accuracy of the data appear to deteriorate. The preliminary ICP-AES Zn concentration measurements allowed all samples to be spiked and analyzed with near-optimal proportion of DS-derived Zn $(P \approx 0.55)$.
Fig. 2 The $\mathrm{Zn}$ isotope data $\left(\delta^{66} \mathrm{Zn}\right.$ values) determined for London $\mathrm{Zn}$-DS mixtures vs. time of data acquisition for two measurement sessions that had duration of $\mathbf{a} 3 \mathrm{~h}$ and $\mathbf{b} 23 \mathrm{~h}$. In b, the measured $\delta^{66} \mathrm{Zn}$ values (filled symbols) are corrected for both the absolute offset and the drift in mass bias behavior (open symbols). This improves the precision of the dataset to $\pm 0.04 \%$ o (2 SD, open symbols)
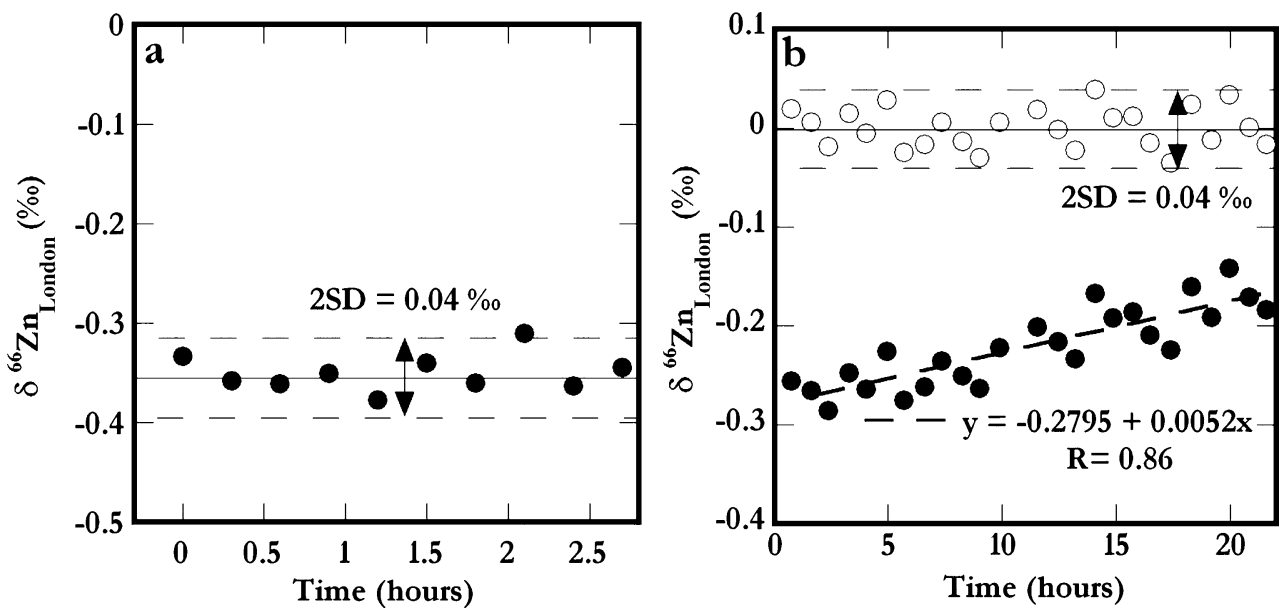
Table $3 \mathrm{Zn}$ isotope data acquired during this study

\begin{tabular}{lllll}
\hline & $\begin{array}{l}\text { Mass bias correction } \\
\text { method }\end{array}$ & $\begin{array}{l}\text { Number of sample } \\
\text { aliquots }\end{array}$ & $\begin{array}{l}\delta^{66} \mathrm{Zn}_{\text {Lyon }} \\
(\%)\end{array}$ & $\begin{array}{l}2 \\
\text { SD }\end{array}$ \\
\hline Imperial Zn & DS & 8 & 0.10 & 0.08 \\
London Zn & SSB & 6 & 0.11 & 0.07 \\
& DS & 10 & 0.08 & 0.04 \\
Spec-pure & SSB & 12 & 0.11 & 0.04 \\
& DS & 11 & -7.07 & 0.08 \\
BCR 027 Blend Ore & SSB & 6 & -6.96 & 0.07 \\
Basalt from East Pacific Rise (NHM & DS & DS & 0.25 & 0.06 \\
SO 40 31D) & & 1 & 0.29 & 0.07 \\
Ryegrass BCR 281 & DS & & & \\
Soil sample 1 & & 7 & 0.40 & 0.09 \\
Bulk & DS & 1 & & 0.34 \\
Leach & DS & 1 & 0.60 & 0.08 \\
Soil sample 2 & & & & 0.11 \\
Bulk & DS & 1 & 0.37 & 0.58 \\
Leach & DS & 1 &
\end{tabular}

Analysis of single-element standards

\section{Comparisons of old and new in-house standards}

Previous $\mathrm{Zn}$ isotope work in our laboratory used an "Imperial Zn" solution prepared from Alfa Aesar Puratronic $\mathrm{Zn}$ wire as the in-house reference material [9, 37]. The isotope composition of Imperial $\mathrm{Zn}$ was calibrated relative to the Johnson Matthey (JMC) Zn standard solution (batch 3-0749L) of the École Normale Supérieure Lyon Earth Science Laboratory (denoted "Lyon Zn" hereafter), thereby allowing inter-laboratory comparison. Numerous measurements performed using an Isoprobe MC-ICPMS over the last three years yielded $\delta^{66} \mathrm{Zn}=-0.06 \pm 0.05 \%$ for Lyon $\mathrm{Zn}$ relative to Imperial $\mathrm{Zn}$.

The newly prepared London $\mathrm{Zn}$ solution will be used as the in-house $\mathrm{Zn}$ isotope standard from this point forward, and several measurements were therefore made to calibrate the $\mathrm{Zn}$ isotope composition of London $\mathrm{Zn}$ relative to both Lyon $\mathrm{Zn}$ and Imperial Zn (Table 3). DS and SSB analyses reveal that the isotopic composition of Imperial $\mathrm{Zn}$ is identical to London $\mathrm{Zn}$ within analytical uncertainty. Most importantly, analyses of London $\mathrm{Zn}$ relative to Lyon $\mathrm{Zn}$ yielded $\delta^{66} \mathrm{Zn}_{\text {Lyon }}=0.08 \pm 0.04 \%$ using the DS protocol. This value is identical to data acquired during the course of this study by SSB on the Nu Plasma MC-ICPMS (Table 3) and demonstrates that the DS method is able to provide accurate $\mathrm{Zn}$ isotope data for pure $\mathrm{Zn}$ standard solutions. All samples were measured relative to London $\mathrm{Zn}$, but to facilitate inter-laboratory comparison, the results were then recalculated and reported relative to Lyon $\mathrm{Zn}$ in Table 3.

\section{Highly fractionated industrial single-element solution}

Of particular interest are the results for the Spec-pure singleelement solution with highly fractionated $\mathrm{Zn}$. The DS protocol yielded $\delta^{66} \mathrm{Zn}_{\text {Lyon }}=-7.07 \%$ o $( \pm 0.08,2 \mathrm{SD} ; \pm 0.02,2 \mathrm{SE} ; n=11)$, while SSB protocols yielded $\delta^{66} \mathrm{Zn}_{\text {Lyon }}=-7.96 \%$ o $( \pm 0.07$, $2 \mathrm{SD} ; \pm 0.03,2 \mathrm{SE}, n=6$, Table 3 ). Each average value is based on multiple (between three and six) analyses of $n$ separate stock solution aliquots. The number of measurements that were carried out for the Spec-pure $\mathrm{Zn}$ solution justifies the use

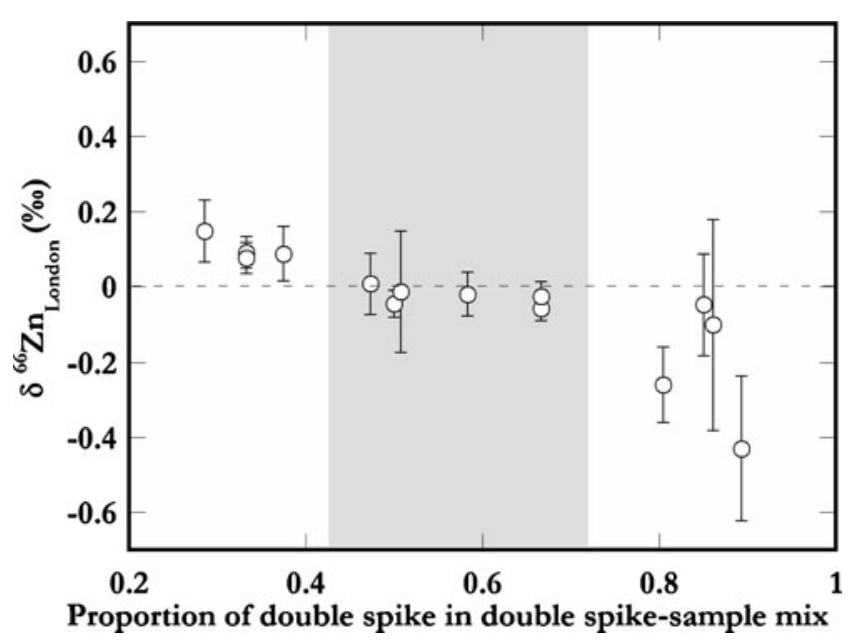

Fig. 3 The $\mathrm{Zn}$ isotope data obtained for various London $\mathrm{Zn}-\mathrm{Zn}$ double-spike mixtures. The molar proportion of spike-derived $Z n$ vs. total $\mathrm{Zn}$ varied between 0.2 and 1 . The results are reported relative to data acquired at optimal proportion $(0.55)$. The error bars denote the internal precision $( \pm 2 \mathrm{SE})$ of the analyses 
of a 2SE error envelope to characterize the uncertainty of averages. Figure $4 \mathrm{a}$ shows the DS and the SSB data in three isotope diagrams of $\delta^{67} \mathrm{Zn}$ vs. $\delta^{66} \mathrm{Zn}$ and $\delta^{68} \mathrm{Zn}$ vs. $\delta^{64} \mathrm{Zn}$. The results obtained for Spec-pure $\mathrm{Zn}$ by SSB and the DS approach are significantly different at the 95\% confidence level. The DS protocol inherently forces all points to lie on an exponential mass-dependent fractionation curve, while the SSB analyses produced three independent $\mathrm{Zn}$ isotope ratios.

Theoretical mass-dependent fractionation lines for equilibrium and kinetic systems diverge as the magnitude of fractionation increases (Fig. 4). These fractionation lines are defined by the following equation:

$\delta^{\mathrm{x} / 64}=\left[\left(\frac{\delta^{\mathrm{y} / 64}}{10^{3}}\right)^{\beta}-1\right] \times 10^{3}$

Here, $x$ and $y$ represent the isotopes of mass $m_{x}$ and $m_{y}$, and $\beta$ is given by $\left[\ln \left(m_{y} / m_{64}\right)\right] /\left[\ln \left(m_{x} / m_{64}\right)\right]$ for kinetic or $(1 /$ $\left.m_{64}-1 / m_{y}\right) /\left(1 / m_{64}-1 / m_{x}\right)$ for equilibrium systems [38].

The Spec-pure $\mathrm{Zn}$ isotope data $\left(\delta^{68} \mathrm{Zn}\right)$ obtained by SSB lie off the mass-dependent fractionation curves that describe equilibrium and kinetic isotope fractionation, or any intermediate mass bias relationship (Fig. 4a). Possible reasons include (1) spectral interferences on one or more isotopes during the analyses, (2) mass-independent isotope effects, or (3) complicated isotope fractionation processes characterized by multiple stages with different $\beta$ values, which may have occurred during the production and purification of the Spec-pure $\mathrm{Zn}$ sample.

Spectral interferences are not responsible for the offset of the Spec-pure Zn SSB data seen in Fig. 4a. This is demonstrated by (1) the observation that only the Specpure but not the Lyon $\mathrm{Zn}$ data plot off the fractionation lines (Fig. 4a, b), while (2) elements that can form interfering species, such as $\mathrm{Mg}, \mathrm{Al}, \mathrm{Ti}, \mathrm{V}, \mathrm{Cr}$, and $\mathrm{Ba}$, are present at similar insignificant levels in the solutions of Spec-pure Zn, London Zn, Lyon Zn, and the Zn DS (measured using an ion counter on the $\mathrm{Nu}$ Plasma MC-ICPMS, data not shown). Mass-independent isotope effects related to nuclear volume are also unlikely to cause the offset because such effects are essentially insignificant for the first row d-block metals [39].

It is more likely that Spec-pure $\mathrm{Zn}$ was affected by multiple, and possibly repetitive, isotope fractionation processes that occurred during isolation and purification of the $\mathrm{Zn}$ metal. This conclusion is supported by close inspection of data for other highly fractionated $\mathrm{Zn}$ solutions analyzed in various laboratories with different instruments (Fig. 4c). Values for Romil $\mathrm{Zn}$ measured by standard sample bracketing on the Isoprobe at Imperial College (Table 3) and the results of Sonke et al. [40], for the most fractionated $\mathrm{Zn}$ standard measured to date (JMC LMTG- 10k), also cluster below the kinetic mass fractionation curve. Furthermore, similar results were obtained for $\mathrm{Cd}$ metal that was the fractionated residue of $\mathrm{Cd}$ evaporation into vacuum [41].

The unusual isotopic characteristics of the Spec-pure $\mathrm{Zn}$ sample can be explained if two processes, such as evaporation and condensation, with slightly different $\beta$ values (see Eq. 5) affected the $\mathrm{Zn}$ isotope composition during the production and purification. As an example, if we assume that (1) evaporation and condensation are characterized by $\beta$ values of 1.95 and 1.97 , respectively, and (2) that condensation and evaporation involve a $+1 \%$ and $-1 \%$ shift in $\delta^{66} \mathrm{Zn}$, respectively. Hence, the overall shift in $\delta^{66} \mathrm{Zn}$ is 0 , but the resulting net change for $\delta^{68} \mathrm{Zn}$ is about $-0.02 \%$. The offset observed for Spec-pure $\mathrm{Zn}$ from the kinetic mass-dependent line is approximately $0.09 \%$ $\left(\delta^{68} \mathrm{Zn}\right)$, which can be readily produced by multiple evaporation/condensation cycles.

Stable isotope data acquired by the DS procedure cannot detect such effects because the data reduction assumes that the natural isotope fractionation is adequately described by a single kinetic mass fractionation curve, which connects sample and starting material (Siebert et al. [31]). Our finding implies that a subtle breakdown of the DS data reduction technique occurs, when it is applied to large isotopic fractionations, which are produced by multiple processes with different mass fractionation characteristics ( $\beta$ values $)$.

Sample analysis: reproducibility and accuracy

The $\mathrm{Zn}$ isotope data obtained for geological and biological reference materials are summarized in Table 3. Four separate aliquots from the BCR-027 Zn blend digest were purified and analyzed over the course of three separate analytical sessions. The average $\delta^{66} \mathrm{Zn}_{\text {Lyon of }}$ these four measurements is $+0.25 \pm 0.06 \%$ (2SD), and this agrees well with the value of $\delta^{66} \mathrm{Zn}_{\text {Lyon }}=+0.33 \pm 0.07 \%$ (2SD) obtained by Chapman et al. [6] for the same sample using SSB.

The basalt SO 40 31D from the East Pacific Rise was measured during a single analytical session and yielded $\delta^{66} \mathrm{Zn}_{\text {Lyon }}=+0.29 \pm 0.07 \%$ o (2SD). This value is within the range of $\mathrm{Zn}$ isotope compositions reported for other basalt samples (0.26-0.58\%; summarized by Cloquet et al. [2]).

Seven analyses of the ryegrass BCR 281 conducted on three separate analytical sessions gave a mean result of $+0.40 \pm 0.09 \%$ (2SD) for $\delta^{66} \mathrm{Zn}_{\text {Lyon. A slightly heavier }}$ average value of $+0.71 \pm 0.17 \%$ (2SD) was reported by Peel et al. [42] for the same material. Isotopic heterogeneity in the plant standard could be the reason for the difference. We expect the DS method to provide the most reliable $\mathrm{Zn}$ isotope measurements for plant material, given 
Fig. 4 The $\mathrm{Zn}$ isotope compositions (open symbols for $\delta^{67} \mathrm{Zn}$ vs. $\delta^{66} \mathrm{Zn}$; closed symbols for $\delta^{68} \mathrm{Zn}$ vs. $\delta^{66} \mathrm{Zn}$ ) obtained by DS and by standard sample bracketing (SSB) for a Spec-pure Zn and b Lyon Zn. For Lyon Zn, only SSB results are shown for clarity (results by the DS methodology are shown in Table 3). The mean results of multiple analyses are shown. The error bars denote the $\pm 2 \mathrm{SE}$ uncertainty limits (see text for details). Panel $\mathbf{c}$ presents a compilation of $\mathrm{Zn}$ isotope data from this study (Spec-pure), previous work on Romil $\mathrm{Zn}$, and another pure $\mathrm{Zn}$ standard solutions with highly fractionated isotope compositions (JMC LMTG-10K Zn; Sonke et al. [40]). Note that the data of all three $\mathrm{Zn}$ standards appear to plot below the kinetic isotope fractionation line. The kinetic and equilibrium fractionation curves were calculated with Eq. 5 using $\beta=1.490$ (kinetic) and 1.479 (equilibrium) for $\delta^{67} \mathrm{Zn}$ vs. $\delta^{66} \mathrm{Zn}$ and $\beta=1.971$ (kinetic) and 1.942 (equilibrium) for $\delta^{68} \mathrm{Zn}$ vs. $\delta^{66} \mathrm{Zn}$

the reproducibility and accuracy of the data demonstrated here.

The $\mathrm{Zn}$ isotope composition of the Rothamsted soil: bulk sample and acid leachates

A standard method for the determination of the $\mathrm{Zn}$ pool available to rice plants is the extraction of $\mathrm{Zn}$ from the soil by leaching with $0.1 \mathrm{M} \mathrm{HCl}$ [27]. We used this method to investigate the isotopic composition of the $\mathrm{Zn}$ reservoir accessible to plants. The acid extracts $\mathrm{Zn}$ adsorbed on soil surfaces, such as amorphous Fe oxides, and organically bound $\mathrm{Zn}$. For the Rothamsted soil, the $\mathrm{Zn}$ isotope composition of the leach fraction was on average $\sim 0.2 \%$ heavier $\left(\delta^{66} \mathrm{Zn}\right)$ compared to the bulk soil (Table 3). In previous studies, enrichment of heavy $\mathrm{Zn}$ isotopes due to the long-term deposition of anthropogenic atmospheric $\mathrm{Zn}$ has been reported [18, 40]. The atmospheric deposition of $\mathrm{Zn}$ was linked to increases in the soil Zn content and other metals at Rothamsted UK from at least the beginning of twentieth century [43, 44]. The control plot (no additions of any fertilizers) of Rothamsted's Broadbalk continuous wheat experiment showed an increase of $40 \%$ in the total $\mathrm{Zn}$ content between 1,865 and $2,000 \mu \mathrm{g} \mathrm{g}^{-1}$ [43]. Our results thus suggest that the $\mathrm{Zn}$ deposited by atmospheric pollution mainly remains loosely bound and is released in the $0.1 \mathrm{M} \mathrm{HCl}$ leach fraction, giving rise to the heavier isotopic signature observed in the acid leachate (Table 3).

A further interesting observation is made when evaluating mass balance calculations based on the soil fractions. Bulk soil and leach fractions of the Rothamsted soil have concentrations of $\sim 105$ and $26 \mu \mathrm{g} \mathrm{g} \mathrm{g}^{-1}$, respectively. Combining these data with the $\mathrm{Zn}$ isotope data (Table 3) in a mass balance calculation yields an undissolved soil fraction (after leaching) that possesses a $\delta^{66} \mathrm{Zn}_{\text {Lyon }}$ of $\sim 0.28 \%$. This value agrees with the $\delta^{66} \mathrm{Zn}$ values reported for basalts both here and in previous studies $[2,6]$.
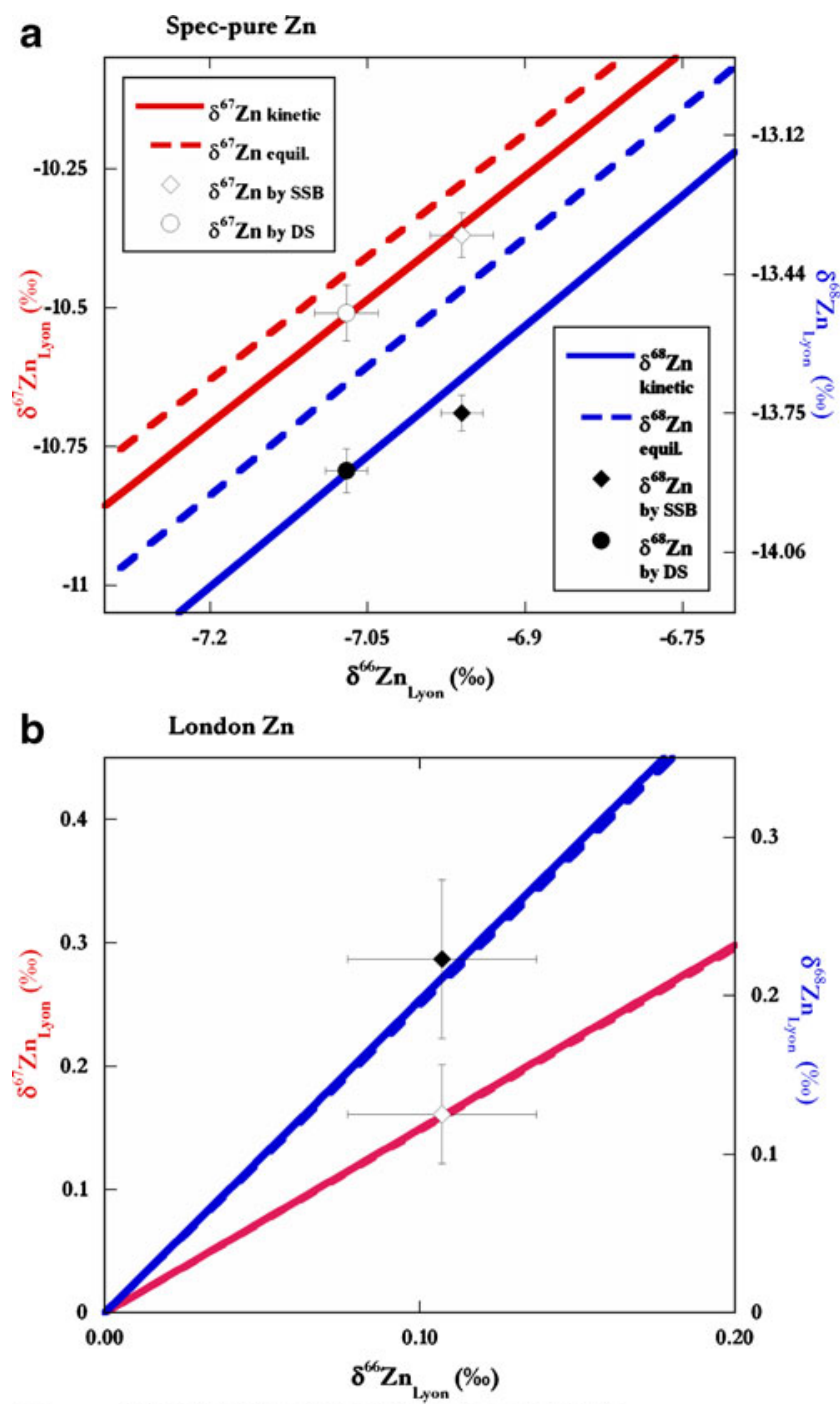

C Highly fractionated single element standards

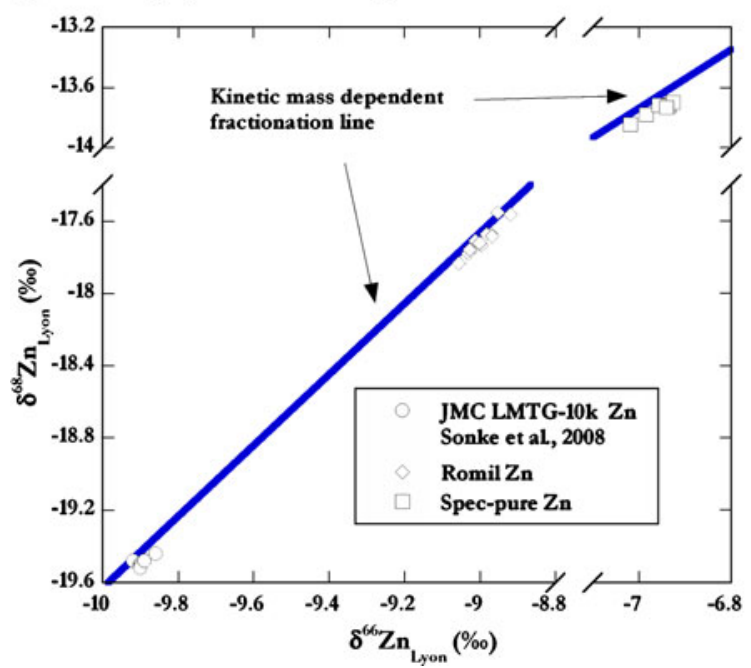




\section{Conclusions}

A $\mathrm{Zn}$ DS technique was developed for isotope analysis of a range of samples with the aim to overcome the instrumental mass bias problems, which are associated with the different sample matrices and can cause inaccuracies. Relative to previous $\mathrm{Zn}$ double-spike methods, this technique makes significant improvements regarding both ease of measurement and the precisions obtained. Single-element standards and various natural samples were analyzed to test the method. Results obtained from DS measurements of industrial $\mathrm{Zn}$ standard solutions were all consistent, within uncertainty ( $\pm 0.05 \%$ to $0.10 \%$ o for $\delta^{66} \mathrm{Zn}$; 2SD), with data obtained in this and previous studies using alternative methods of mass bias correction. Further analyses of the BCR 027 Blend Ore reference material and a basalt sample from the East Pacific Rise yielded data that confirm previously reported values. Results from several digests of the BCR 281 ryegrass standard yielded $\delta^{66} \mathrm{Zn}_{\text {Lyon }}=0.40 \pm 0.09 \%$ ( $2 \mathrm{SD}, n=7$ ). Taken together, these results validate the new DS methodology, as the technique yields precise and accurate $\mathrm{Zn}$ isotope ratio results.

The highly fractionated Spec-pure Zn standard solution, however, yielded a small but significant difference between results obtained by the DS and SSB measurement protocols. The $\mathrm{Zn}$ isotope composition determined by SSB falls below the theoretical kinetic mass-dependent fractionation line $\left(\delta^{66} \mathrm{Zn}_{\text {Lyon }}=-7.06 \pm 0.07 \%\right.$ ), and this is probably due to repetitive fractionation events that occurred during purification of Spec-pure $\mathrm{Zn}$. The slightly different DS result $\left(\delta^{66} \mathrm{Zn}_{\text {Lyon }}=-7.17 \pm 0.08 \%\right.$ o $)$ for this sample is therefore most likely an analytical artifact of the DS data reduction routine because the latter assumes that the isotope fractionation is generated by a one-step process, which induces only kinetic isotope effects. Caution is therefore required if the DS procedure is applied to samples, which are strongly fractionated due to overprinting by multiple fractionation events.

The DS methodology was applied to estimate the isotopic pool of $\mathrm{Zn}$ available to plants from a soil. Mild acid leaching was used to extract the likely pool of bioavailable $\mathrm{Zn}$, which was found to have an isotope composition $0.2 \%$ o heavier than the bulk soil. Given the history of the soil, we suggest that the slightly heavier composition in the leachate originates from deposited atmospheric pollution.

Acknowledgements We thank Terry Williams at the Natural History Museum for his support and Javier Cuadros for donating the basalt sample. Financial support from Imperial College via a Ph.D. scholarship and The Natural History Museum (London) is gratefully acknowledged. We thank the two anonymous referees for their thoughtful and constructive comments that helped to significantly improve the manuscript. Rothamsted Research is an institute of the Biotechnology and Biological Sciences Research Council of the UK. $\mathrm{T}$ Arnold dedicates this manuscript in memory of May Edginton.
Open Access This article is distributed under the terms of the Creative Commons Attribution Noncommercial License which permits any noncommercial use, distribution, and reproduction in any medium, provided the original author(s) and source are credited.

\section{References}

1. Albarède F (2004) The stable isotope geochemistry of copper and zinc. Rev Mineral Geochem 55:409-427

2. Cloquet C, Carignan J, Lehmann MF, Vanhaecke F (2008) Variation in the isotopic composition of zinc in the natural environment and the use of zinc isotopes in biogeosciences: a review. Anal Bioanal Chem 390:451-463

3. Williams RJP, Fraùsto da Silva JJR (2006) The chemistry of evolution. Elsevier, Amsterdam

4. Balistrieri LS, Borrok DM, Wanty RB, Ridley WI (2008) Fractionation of $\mathrm{Cu}$ and $\mathrm{Zn}$ isotopes during adsorption onto amorphous $\mathrm{Fe}(\mathrm{III})$ oxyhydroxide: experimental mixing of acid rock drainage and ambient river water. Geochim Cosmochim Acta 72:311-328

5. Bermin J, Vance D, Archer C, Statham PJ (2006) The determination of the isotopic composition of $\mathrm{Cu}$ and $\mathrm{Zn}$ in seawater. Chem Geol 226:280-297

6. Chapman JB, Mason TFD, Weiss DJ, Coles BJ, Wilkinson JJ (2006) Chemical separation and isotopic variations of $\mathrm{Cu}$ and $\mathrm{Zn}$ from five geological reference materials. Geostandard Newslett 30:5-16

7. Cloquet C, Carignan J, Libourel G (2006) Isotopic composition of $\mathrm{Zn}$ and $\mathrm{Pb}$ atmospheric depositions in an urban/periurban area of northeastern France. Environ Sci Technol 40:6594-6600

8. Gelabert A, Pokrovsky OS, Viers J, Schott J, Boudou A, FeurtetMazel A (2006) Interaction between zinc and freshwater and marine diatom species: surface complexation and $\mathrm{Zn}$ isotope fractionation. Geochim Cosmochim Acta 70:839-857

9. Gioia S, Weiss D, Coles B, Arnold T, Babinski M (2008) Accurate and precise zinc isotope ratio measurements in urban aerosols. Anal Chem 24:9776-9780

10. John SG, Geis RW, Saito MA, Boyle EA (2007) Zinc isotope fractionation during high-affinity and low-affinity zinc transport by the marine diatom Thalassiosira oceanic. Limnol Oceanog 52:2710-2714

11. John SG, Rouxel OJ, Craddock PR, Engwall AM, Boyle EA (2008) Zinc stable isotopes in seafloor hydrothermal vent fluids and chimneys. Earth Planet Sci Lett 269:17-28

12. Juillot F, Marechal Ponthieu M, Cacaly S, Morin G, Benedetti M, Hazemann JL, Proux O, Guyot F (2008) Zn isotope fractionation caused by sorption on goethite and 2-lines ferrihydrite. Geochim Cosmochim Acta 72:4886-4900

13. Maréchal CN, Telouk P, Albarede F (1999) Precise analysis of copper and zinc isotopic compositions by plasma-source mass spectrometry. Chem Geol 156:251-273

14. Maréchal CN, Douchet D, Nicolas E, Albarède F (2000) The abundance of zinc isotopes as a marine biogeochemical tracer. Geochem Geophys Geosys 1:1999GC-000029GC

15. Pichat S, Douchet C, Albarede F (2003) Zinc isotope variations in deep-sea carbonates from the Eastern Equatorial Pacific over the last 175 ka. Earth Planet Sci Lett 210:167-178

16. Weiss DJ, Rausch N, Mason TFD, Coles BJ, Wilkinson JJ, Ukonmaanaho L, Arnold T, Nieminen TM (2007) Atmospheric deposition and isotope biogeochemistry of zinc in ombrotrophic peat. Geochim Cosmochim Acta 71:3498-3517

17. Weiss DJ, Rehkämper M, Schoenberg R, McLaughlin M, Kirby J, Campbell PGC, Arnold T, Chapman J, Peel K, Gioia S (2008) 
Application of non-traditional stable isotope systems to the study of sources and fate of metals in the environment. Environ Sci Technol 42:655-664

18. Peel K, Weiss D, Sigg L (2009) Zinc isotope composition of settling particles as a proxy for biogeochemical processes in lakes: insights from the eutrophic Lake Greifen, Switzerland. Limnol Oceanog 54:1699-1708

19. Pokrovsky OS, Viers J, Freydier R (2005) Zinc stable isotope fractionation during its adsorption on oxides and hydroxides. $\mathrm{J}$ Colloid Interface Sci 291:192-200

20. Luck JM, Othman BD, Albarede F (2005) $\mathrm{Zn}$ and $\mathrm{Cu}$ isotopic variations in chondrites and iron meteorites: early solar nebula reservoirs and parent-body processes. Geochim Cosmochim Acta 69:5351-5363

21. Arnold T, Kirk GJD, Wissuwa M, Frei M, Zhao FJ, Mason TFD, Weiss DJ (2010) Evidence for the mechanisms of zinc uptake by rice using isotope discrimination. Plant Cell Environ 3:370-381

22. Moynier F, Pichat S, Pons M, Fike D, Balter V, Alberède F (2008) Isotopic fractionation and transport mechanisms of $\mathrm{Zn}$ in plants. Chem Geol 267:125-130

23. Ohno T, Shinohara A, Chiba M, Hirata T (2005) Precise Zn isotopic ratio measurements of human red blood cell and hair samples by multiple collector ICP mass spectrometry. Anal Sci 21:425-428

24. Weiss DJ, Mason TFD, Zhao FJ, Kirk GJD, Coles BJ, Horstwood MSA (2005) Isotopic discrimination of zinc in higher plants. New Phytol 165:703-710

25. Viers J, Oliva P, Nonell A, Gelabert A, Sonke JE, Freydier R, Gainville R, Dupre B (2007) Evidence of Zn isotopic fractionation in a soil-plant system of a pristine tropical watershed (Nsimi, Cameroon). Chem Geol 239:124-137

26. Archer C, Vance D (2004) Mass discrimination correction in multiple-collector plasma source mass spectrometry: an example using $\mathrm{Cu}$ and $\mathrm{Zn}$ isotopes. J Anal At Spectrom 19:656-665

27. Dobermann A, Fairhurst T (2000) Rice nutrient disorders and nutrient management. Potash and Phosphate Institute and International Rice Research Institute, Singapore

28. Galer SJG (1999) Optimal double and triple spiking for high precision lead isotopic measurement. Chem Geol 157:255-274

29. Rudge J, Reynolds BC, Bourdon B (2009) The double spike toolbox. Chem Geol 265:420-431

30. Rosman KJR (1972) Survey of isotopic and elemental abundance of zinc. Geochim Cosmochim Acta 37:801-819

31. Siebert C, Nagler TF, Kramers JD (2001) Determination of molybdenum isotope fractionation by double-spike multicollector inductively coupled plasma mass spectrometry. Geochem Geophys Geosys 2:2000GC000124
32. Weiss DJ, Kober B, Gallagher K, Dolgopolova A, Mason TFD, Coles BJ, Kylander ME, LeRoux G, Spiro B (2004) Accurate and precise $\mathrm{Pb}$ isotope measurements in environmental samples using MC-ICP-MS. Intern J Mass Spectrom 232:205-215

33. Russell RD (1971) Systematics of double spiking. J Geophys Res 76:4949-4955

34. Ripperger S, Rehkämper M (2007) Precise determination of cadmium isotope fractionation in seawater by double spike MCICPMS. Geochim Cosmochim Acta 71:631-642

35. Schoenberg R, Zink S, Staubwasser M, von Blanckenburg F (2008) The stable Cr isotope inventory of solid Earth reservoirs determined by double spike MC-ICPMS. Chem Geol 249:294 306

36. Wombacher F, Rehkämper M, Mezger K, Munker C (2003) Stable isotope compositions of cadmium in geological materials and meteorites determined by multiple-collector ICPMS. Geochim Cosmochim Acta 67:4639-4654

37. Mason TFD, Weiss DJ, Horstwood M, Parrish PR, Russell SS, Mullane E, Coles BJ (2004) High-precision $\mathrm{Cu}$ and $\mathrm{Zn}$ isotope analysis by plasma source mass spectrometry part 2. Correcting for mass bias effects. J Anal At Spectrom 19:218-226

38. Young ED, Galy A, Nagahara H (2002) Kinetic and equilibrium mass-dependent isotope fractionation laws in nature and their geochemical and cosmochemical significance. Geochim Cosmochim Acta 66:1095-1104

39. Schauble EA (2007) Role of nuclear volume in driving equilibrium stable isotope fractionation of mercury, thallium, and other very heavy elements. Geochim Cosmochim Acta 71:2170-2189

40. Sonke JE, Sivry Y, Viers J, Freydier R, Dejonghe L, Andre L, Aggarwal JK, Fontan F, Dupre B (2008) Historical variations in the isotopic composition of atmospheric zinc deposition from a zinc smelter. Chem Geol 252:145-157

41. Wombacher F, Rehkämper M, Mezger K (2004) Determination of mass-dependence of cadmium isotope fractionation during evaporation. Geochim Cosmochim Acta 68:2349-2357

42. Peel K, Weiss D, Chapman J, Arnold T, Coles B (2008) A simple combined sample-standard bracketing and inter-element correction procedure for accurate mass bias correction and precise $\mathrm{Zn}$ and $\mathrm{Cu}$ isotope ratio measurements. J Anal At Spectrom 23:103-110

43. Fan MS, Zhao FJ, Fairweather-Tait SJ, Poulton PR, Dunham SJ, McGrath SP (2008) Evidence of decreasing mineral density in wheat grain over the last 160 years. J Trace Elem Med Biol 22:315-324

44. Jones KC, Symon CJ, Johnston AE (1987) Retrospective analysis of an archived soil collection-1 metals. Sci Total Environ 61:131-144 